\title{
Against a high-risk strategy in the prevention of suicide
}

\author{
Navneet Kapur and Allan House
}

\begin{abstract}
Standard approaches to the prevention of suicide have concentrated on the rigorous assessment and manogement of suicidal risk. Using deliberate selfharm as a specific example, we discuss the relative merts of this 'high-risk' strategy and compare if with a population-based preventive strategy. We conclude that a combined approach offers the best hope for reducing the rate of suicide, although it may not fit ecsilly with modical models of care.
\end{abstract}

Two recent articles in the Psychiatric Bulletin have argued that our best hope of reducing suicide is by further refinement of a 'high-risk' approach; that is, by improving the assessment and management of suicide risk in clinical populations (Appleby, 1997; Morgan, 1997). In this paper we suggest that an exclusive preoccupation with risk and risk factors may not be the most effective way to proceed, and present an alternative strategy.

\section{High-risk strategy}

In preventive medicine, the 'high-risk' strategy involves applying risk assessment to a population, and then focusing intervention on those identified as being at greatest risk of poor outcomes (Rose, 1992). The advantages of a high-risk strategy are clear: it offers a costeffective use of resources since only a minority of individuals are targeted; it avoids unnecessary and potentially harmful treatment in those who do not need it; it leads to interventions that are more likely to be tailored to the needs of the individual. Treating patients identified as being at risk matches our traditional disease-based model of medical care.

Unfortunately, there are serious problems with an exclusively high-risk strategy. First, the lower risk, higher volume group are excluded even though they represent a larger absolute number of those with poor outcomes, and therefore a greater population burden. Any intervention targeted at the high-risk group alone may only make a small contribution to reducing the overall incidence of the disease in the population. Second, instruments screening for the high-risk may be expensive, impractical or lack predictive power. Third, the distinction between high- and low-risk groups may well be an artificial one.

\section{Deliberate self-harm: a worked ezample}

The current approach to deliberate self-harm is a good example of a high-risk strategy. Assessment is usually aimed at identifying demographic and clinical variables thought to be predictive of future suicidal behaviour (Owens et al, 1994). Since only $10-20 \%$ of individuals are identified as being at high risk by the best available screening instruments (Kreitman \& Foster, 1991), a large proportion of patients are now neither admitted to hospital (Owens, 1990) nor offered psychosocial follow-up (House et al, 1992), after hospital attendance for deliberate self-harm. Restricting intervention in this way undoubtedly reduces the immediate burden on psychiatric services and might represent an efficient use of resources. It also avoids unnecessary treatment. Once patients have been identified, treatments can be tailored to the individual; for example, those with alcohol misuse problems can be referred to specialist addiction services, those with major depression treated by psychological or pharmacological means. The high-risk approach is well suited to current models of service provision in psychiatry (Morgan, 1997).

However, the high-risk strategy for deliberate self-harm patients has all the disadvantages we would predict from the basic principles outlined above. Targeting high-risk groups, such as those with enduring affective disorder or those with other specific risk factors, results in large numbers of supposedly low-risk individuals being 'defined out' of care, reducing the impact of suicide prevention strategies. For example. those identified as being at high risk using the Kreitman \& Foster (1991) risk assessment scale account for only $26 \%$ of cases of future suicidal behaviour, the much larger 'low-risk' group accounting for the remainder (Table 1). With intervention restricted to the high-risk group, even assuming that it is totally effective (which is 
Table 1. Number (\%) of men falling into different risk groups on the basis of a risk scale, and numbers (\%) subsequently harming themselves in the different groups (Kreitman \& Foster, 1991)

\begin{tabular}{lrl}
\hline & & $\begin{array}{l}\text { Number with } \\
\text { further episode } \\
\text { of deliberate } \\
\text { self-harm (\%) }\end{array}$ \\
\hline Risk score & $(\%)$ & $8(10.4)$ \\
Low (0-3) & $103(27.2)$ & $49(63.6)$ \\
Middle (4-7) & $239(60.4)$ & $20(26)$ \\
High (8+) & $47(12.4)$ & $77(100)$ \\
All scores & $379(100)$ & \\
\hline
\end{tabular}

improbable), we will reduce the overall rate of suicidal behaviour by at most a quarter.

Screening for risk is based largely on demographic factors and information from clinical interview. It is feasible and not prohibitively expensive. However, available risk measures are poor at predicting repeated suicidal behaviour (positive predictive value $25 \%$ at best (Owens et al, 1994)) and even worse at predicting completed suicide (Dennehy et al, 1996). High relative risks do not equate with high absolute risk because suicide is a relatively uncommon event. For example, the annual suicide rate in the general population is in the region of 10 per 100000 . A relative risk of suicide of 100 in the year following an episode of self-harm seems impressive (Hawton \& Fagg, 1988), but it means that as few as one in 100 self-harming individuals will die by suicide in the following year. Identifying this small proportion by conventional means of risk assessment is likely to be extremely difficult.

Suicide risk may be continuously distributed in a population, in which case a dichotomous distinction between high- and low-risk groups is inaccurate because it fails to take account of degrees of risk. For example, a commonly used criterion for assessing risk is the presence or absence of major depressive disorder. In diagnostic terms someone is either "a case" or not, but it may be that even a "touch of depression" (Rose, 1992), confers some increased risk of suicide.

\section{Alternative approach: population strategy of prevention}

In a population-based strategy, whole populations are targeted rather than just vulnerable (high-risk) individuals. This is potentially powerful because of the number of individuals involved; even very small population shifts can have large effects. To use an example from general medicine, a fall of just $3 \%$ in the mean population blood pressure reduces the population prevalence of hypertension by $25 \%$ (Rose. 1992). Population approaches are also radic since they seek to address underlying causes of phenomenon rather than just its external manifestations. However, the implementation of population approaches may be unacceptable, unfeasible or prohibitively expensive.

What would a population strategy for suicide prevention following deliberate self-harm look like? Limiting the availability of methods of selfharm might have some impact, perhaps by exploiting the ambivalence felt by many of those seeking to end their lives. Gunnell \& Frankel (1994) argue that if sufficient time is gained by making a method less accessible, the suicidal impulse may subside. Specific examples include limiting the prescription of antidepressants which are potentially fatal in overdose, imposing restrictions on over the counter medicines, limiting the number of paracetamol tablets per pack and redesigning car exhaust systems.

Economic and social policy would also need to be considered. Gunnell et al (1995) reported a strong ecological association between suicide and parasuicide, with socio-economic deprivation accounting for much of this relation. They argued that measures aimed at tackling deprivation might be far more effective in reducing suicide rates than any specific clinical interventions. Recently, Lewis et al (1997) have suggested that as many as one in 10 suicides might be attributable in some part to unemployment.

Perhaps one of the most radical changes would involve our clinical management of deliberate self-harm and not just that minority of patients perceived to be at high risk (Kapur et al, 1998). These interventions might be aimed at the underlying causes of the self-harming behaviour. For example, there is evidence to suggest that self-harming individuals are poor at solving interpersonal problems, and generate fewer problem-solving steps than equally depressed non-suicidal patients, when presented with social scenarios (Schotte \& Clum, 1987). 'Problem-solving treatment' (D'Zurilla, 1986) specifically aims to address this deficit and not the suicidality, the psychiatric diagnosis or the external problems themselves. The whole assessment and management process would then become much more inclusive with everyone, not just those with a specific diagnosis, being offered an intervention. However, such strategles may not be wholly compatible with our medical model of managing health problems.

\section{Conclusion}

The high-risk strategy proposed by Morgan (1997) and Appleby (1997) is too limited. It is 


\section{ORIGINAL PAPERS}

undoubtedly good practice to seek to refine clinical skills for assessing suicide risk, but this alone will not lead suicide rates to "look after themselves" (Morgan, 1997). However, strategles that are exclusively population-based may be out of touch with clinical reality because they fail to take individual circumstances into account. Our only real hope of significantly reducing suicide rates is to combine the two approaches. For deliberate self-harm this would mean offering a basic intervention to all those who have harmed themselves, and using clinical skills and risk assessment to identify high-risk individuals who might benefit from more intensive treatment.

\section{Acknowledgements}

We thank Dr D. Owens and an anonymous referee for their helpful comments on an earlier draft of this paper.

\section{References}

APPLEBY, L. (1997) Assessment of suicide risk. Psychiatric Bulletin, 21, 195-196.

Dennehy, J., Appleby, L.. Thomas, C., et al (1996) Casecontrol study of suicide by discharged psychlatric patients. British Medical Journal, 312, 1580.

D'ZURILA. T. J. (1986) Problem Solving Therapy: A Social Competence Approach to Clinical Intervention. New York: Springer.

GunNeLl, D. \& Frankel. S. (1994) Prevention of suicide: aspirations and evidence. British Medical Journal, 308. 1227-1233.

-. Peters, T. J., Kammerung, R. M., et al (1995) Relation between parasuicide, suicide, psychiatric admissions, and socioeconomic deprivation. British Medical Journal, 311, 226-230.
HAWTON, K. \& FAGG, J. (1988) Sulcide, and other causes of death. following attempted suicide. British Joumal of Psychiatry. 162. 359-366.

House, A., OWEns, D. \& STORER, D (1992) Psycho-social intervention following attempted suicide: is there a case for better services? International Review of Psychiatry. 4. 15-22.

KAPUR, N., House, A., Creed, F., et al (1998) The management of deliberate self-poisoning in four teaching hospitals: descriptive study. British Medical Journal, 316, 831-832.

KrEtTMAN, N. \& FOSTER, J. (1991) Construction and selection of predictive scales, with special reference to parasuicide. British Journal of Psychiatry. 159. 185-192.

LEWIS, G., HAWTON, K. \& Jones. P. (1997) Strategles for preventing suicide. British Joumal of Psychiatry, 171. 351-354.

MORGAN, G. (1997) Management of suicide risk. Psychiatric Bulletin, 21, 214-216.

OWENS. D. (1990) Self-harm patients not admitted to hospital. Journal of the Royal College of Physicians of London, 24, 281-283.

-. DENNIS. M. READ, S., et al (1994) Outcome of deliberate self-poisoning: an examination of risk factors for repetition. British Journal of Psychiatry, 165, 797-801.

Rose, G. (1992) The Strategy of Preventue Medictne. Oxford: Oxford Untversity Press.

SchotTE, D. \& CuM, G. (1987) Problem solving skills in suicidal psychiatric patients. Joumal of Consulting and Clinical Psychology. 85, 49-54.

*Navneet Kapur, Lecturer, Department of Psychiatry, Rawnsley Building, Manchester Royal Infirmary, Oxford Road, Manchester M13 9WL; and Allan House, Senior Lecturer. Department of Liaison Psychiatry, Leeds General Infirmary, Leeds

*Correspondence

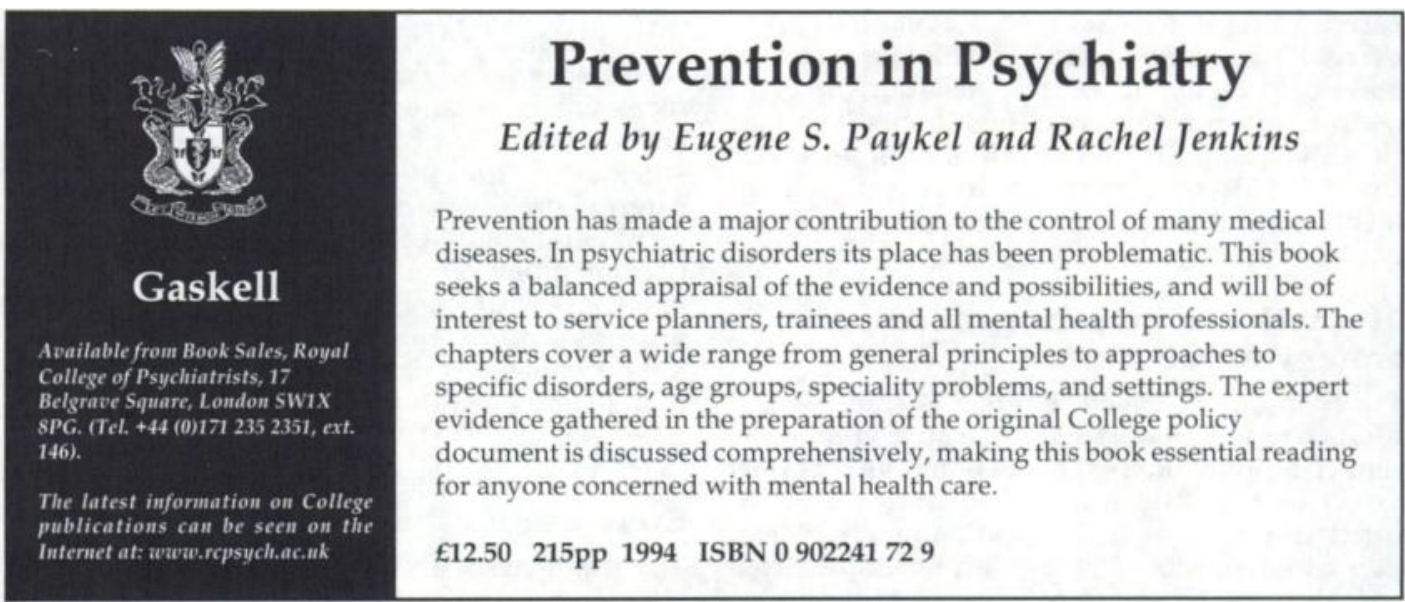

